\title{
Changing maturation reaction norms and the effects of growth history in Alaskan Chinook salmon
}

\author{
Jared E. Siegel ${ }^{1, *}$, Milo D. Adkison ${ }^{2}$, Megan V. McPhee ${ }^{2}$ \\ ${ }^{1}$ South Fork Research, Inc., 44842 SE 145th St., North Bend, WA 98045, USA \\ ${ }^{2}$ College of Fisheries and Ocean Sciences, University of Alaska Fairbanks, 17101 Point Lena Loop Road, Juneau, AK 99801, USA
}

\begin{abstract}
We explored the nature of declines in size and age at maturity in 2 populations of Chinook salmon Oncorhynchus tshawytscha in western Alaska, USA, using multidimensional probabilistic maturation reaction norms (PMRNs) accounting for growth history. Individual growth histories informed by retrospective scale analysis were used to construct PMRNs and to describe the relative influence of different life-history periods on age at maturity. Similar results were found in both populations. Models accounting for growth history uniformly outperformed size-at-age models, suggesting the importance of growth history for the determination of maturation. The second year of marine growth was found to have a disproportionate influence on the age at maturity in both sexes. Males tended to grow more than females in length during the second year at sea, possibly as a consequence of females storing more energy in preparation for the high cost of female gonad development. Finally, we found that growth thresholds for maturation have shown a long-term decline in both sexes. This suggests that declines in the average age at maturity of western Alaskan Chinook salmon may have been caused in part by adaptation to environmental or fisheries-induced selection.
\end{abstract}

KEY WORDS: Oncorhynchus tshawytscha $\cdot$ Size-at-age $\cdot$ PMRN $\cdot$ Age at maturity $\cdot$ Life history · Plasticity $\cdot$ Evolution $\cdot$ Retrospective scale analysis

\section{INTRODUCTION}

Size and age at maturity are important traits in populations subject to fisheries management. Older individuals are generally larger, leading to greater reproductive success and higher value to harvesters, but delayed maturation increases the probability of mortality prior to reproduction (Stearns 1992). Pacific salmon Oncorhynchus spp. have demonstrated considerable variation in size and age at maturity over the last century (Ricker 1981, Bigler et al. 1996, Lewis et al. 2015, Jeffrey et al. 2017). Declines in average size over the latter half of the $20^{\text {th }}$ century have prompted concern over the effects of hatchery production (density-dependent growth; Bigler et al. 1996) and size-selective harvest (Law 2007, Heino et

*Corresponding author: derajlegeis@gmail.com al. 2015). However, ocean conditions also influence growth (Wells et al. 2008), and hence age at maturity, in salmon (Otero et al. 2012). Given the economic and cultural significance of salmon (Fobes 1995, Lord 2016), there is substantial interest in better understanding these trends.

Age at maturity in salmon has both heritable and plastic components (Hankin et al. 1993, Carlson \& Seamons 2008, Berejikian et al. 2011), with individual variation in response to environmental experience. The capacity to mature is constrained by accrual of sufficient energy stores during critical life history periods, and maturation is delayed if energy stores are insufficient (Thorpe 1994). Somatic and gonadal growth are both constrained by energy acquisition; thus, faster-growing individuals are more

() The authors 2018. Open Access under Creative Commons by Attribution Licence. Use, distribution and reproduction are unrestricted. Authors and original publication must be credited. 
likely to mature at a younger age, but generally at a smaller final size, than their later-maturing counterparts. Accordingly, the determination of age at maturity in salmonids is often described as a conditional strategy, where the heritable relationship between growth and age at maturity evolves to optimize the tradeoff between increased reproductive success with size versus increased mortality risk before reproduction (Stearns 1992).

Probabilistic maturation reaction norms (PMRNs) are an empirical method used to distinguish genetic and plastic influences on age at maturity in fish populations (Heino et al. 2002). PMRNs describe the relationship between individual size-at-age and the probability of becoming mature. PMRNs help disentangle plastic effects from genetic effects on maturation because a major source of plasticity in the age at maturity is variation in growth conditions (Heino \& Dieckmann 2008). Temporal shifts in PMRNs have been used to suggest adaptive changes in maturation reaction norms, typically as a consequence of fisheries-induced evolution (e.g. Sharpe \& Hendry 2009, Kendall et al. 2014). However, some studies suggest that shifts in PMRNs could be attributed to plastic responses to other environmental influences on age at maturity (Kuparinen \& Merilä 2007). Accordingly, the PMRN method has been expanded to include other factors, such as body condition (Grift et al. 2007, Mollet et al. 2007, Vainikka et al. 2009) and temperature (Mollet et al. 2007, Tobin \& Wright 2011).

Thorpe (1994) argued that growth rate during key periods, a measure of current performance, may be more important than size-at-age, a measure of past performance, for inhibiting or promoting maturation in salmonids, and this idea has empirical support (Morita \& Fukuwaka 2006, Shearer et al. 2006). This complicates PMRNs, because a single size-at-age can be achieved by different growth trajectories (Morita \& Fukuwaka 2006, Kuparinen et al. 2008). Consequently, it may be important to include growth history in PMRN models when possible to help distinguish environmentally induced plastic changes in maturation from evolutionary responses (Kuparinen et al. 2008, but see Olsen et al. 2014). Pacific salmon research offers an opportunity to refine PMRNs by incorporating individual growth histories using existing monitoring and data collection efforts. Their anadromous and semelparous life histories (reviewed by Quinn 2005) make it feasible to quantify mature adults using monitoring methods in freshwater (e.g. Williams \& Shelden 2011, Mears 2013). Fish scales, which are commonly collected in Pacific salmon populations primarily to provide information on age, can be used to describe the growth history of individuals through retrospective scale analysis methods (Hagen et al. 2001, Borgerson et al. 2014). Furthermore, management agencies often collect scale samples from a single population over many years, allowing researchers to relate growth to environmental variables (e.g. Ruggerone et al. 2007, Agler et al. 2013, Siegel et al. 2017) and to investigate the role that changing growth history might play in long-term trends of declining age and size in salmon (Morita \& Fukuwaka 2006, McPhee et al. 2016).

In this study, we applied individual growth histories described by retrospective analysis to a PMRNbased investigation of changing size and age in Chinook salmon O. tshawytscha from western Alaska, USA. The 2 populations we studied have demonstrated declining average size and age at maturity, but the relative roles of environmental influences and size-selective harvest are unclear (Howard \& Evenson 2010, Bromaghin et al. 2011, Lewis et al. 2015, McPhee et al. 2016). A previous study (McPhee et al. 2016) did not account for variations in age at maturity over time in an individual-based analysis of growth and age at maturity in females from these populations. We therefore incorporated information from cohort age-composition reconstructions that account for harvest, in order to provide a more comprehensive basis for understanding the relationship between growth, age at maturity, and changing size in both sexes of Chinook salmon from western Alaska. Our specific objectives were to (1) characterize temporal trends in age at maturity in males and females; (2) estimate and compare average annual growth of males and females; (3) quantify and compare size-at-age PMRNs to multidimensional PMRNs that accounted for growth history in males and females; and (4) determine whether the maturation response to growth has changed over 3 decades, using a PMRN summary metric that incorporated average growth history.

\section{MATERIALS AND METHODS}

\section{Biological sampling and annual growth measurements}

We analyzed data from 2 western Alaskan Chinook salmon populations where returning adults have been sampled and counted at weirs over multiple decades: the East Fork of the Andreafsky River (hereafter referred to as the Andreafsky River), since 1994, and the Kogrukluk River, since 1981 (Fig. 1). 


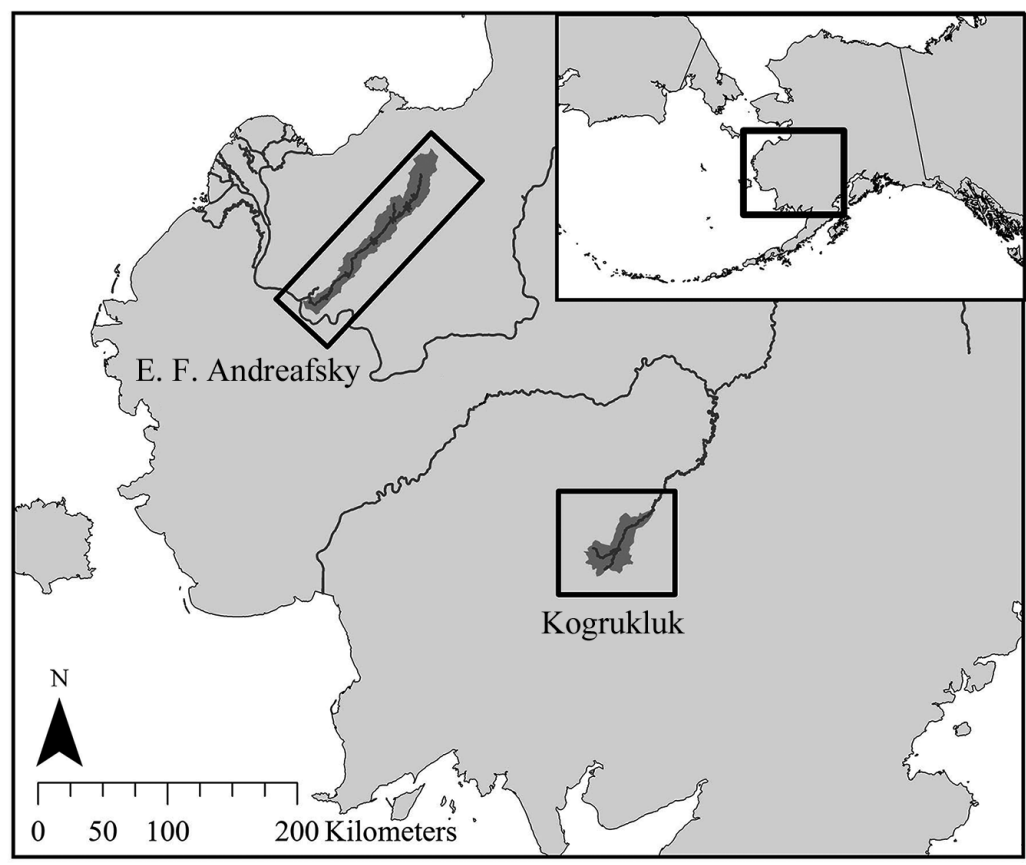

Fig. 1. Locations of the 2 study watersheds in western Alaska, USA: the East Fork (E.F.) of the Andreafsky River (Yukon River drainage) and Kogrukluk River (Kuskokwim River drainage)

The methods for estimating escapement (in-river adult counts) and age, sex, and length distributions are detailed by Mears (2013) for the Andreafsky River and Williams \& Shelden (2011) for the Kogrukluk River. Estimates of total catch and the catch composition (from terminal commercial, subsistence, and sport fisheries) in the Yukon and Kuskokwim River fisheries were produced by the Alaska Department of Fish and Game (e.g. Dubois 2013, Liller et al. 2015). Previous work used both weir and harvest data to estimate the abundance of returning fish (both harvested and not) for each age and sex combination in each brood year (Siegel 2017). We used distribution data from these run reconstructions to inform our growth estimates and maturation models in this study.

We obtained individual age at maturity and growth history data from archived acetate impressions of fish scale collections from the Alaska Department of Fish and Game Mark, Tag, and Age Lab. Salmon scale growth is proportional to somatic growth in length (Fukuwaka \& Kaeriyama 1997, Walker \& Sutton 2016) and accrues in visible seasonal patterns (Fukuwaka \& Kaeriyama 1997), allowing for the estimation of annual growth. We targeted 25 scale samples per sex and predominant age class for each return year in which the weir data were suitable for reconstructing age composition: return years
1994-2012 on the Andreafsky River and 1981-2013 on the Kogrukluk River (Siegel 2017). In some years, our target sample size was not met (Tables S1 \& S2 in the Supplement at www.int-res.com/articles/suppl/m595 p187_supp.pdf). A total of 1916 scales for the Andreafsky River and 3302 scales for the Kogrukluk River were sampled and read following the methods described by McPhee et al. (2016). We define annual growth increments with the notation $g_{a}$ where subscript $a$ represents the annual growth increment, with values of $a$ ranging from $f$ (freshwater growth) to 5 ( $5^{\text {th }}$ year of saltwater growth).

The vast majority of fish in both study populations are believed to spend 1 full year rearing in freshwater before smolting, and we only analyzed individuals with 1 freshwater annulus (>99\% of the samples). Accordingly, an age-4 fish would be one that spent $1 \mathrm{yr}$ rearing in freshwater and $2 \mathrm{yr}$ in saltwater before maturation. Females maturing at ages 5, 6, and 7, and males maturing at ages 4, 5, and 6 represented an estimated $99.0 \%$ of the Kogrukluk River and $97.6 \%$ of the Andreafsky River returns on average (Siegel 2017). We only analyzed information from these primary ages at maturity in this study. Most of the remaining fish in the Andreafsky River were identified as 4 yr old females $(1.7 \%$ on average of the total escapement), many of which were likely misidentified males (R. Brown pers. comm.). Fish ages were subtracted from the year in which returning adults were sampled to infer brood year, the year they were spawned.

\section{Statistical analyses}

Objective 1: characterize temporal trends in age at maturity in males and females

Changes in the mean reconstructed age at maturity of males and females (Siegel 2017) were quantified for the Andreafsky River (brood years 1990-2005) and the Kogrukluk River (brood years 1977-2006) with ordinary least squares linear regression. This analysis, and all subsequent analyses, were performed using the statistical program $\mathrm{R}$ version 3.1.2 (R Core Team 2014). 
Objective 2: estimate and compare average annual growth of males and females

To help interpret the biological significance of differences in scale growth, we fit a linear relationship between scale radius and mid-eye to fork length ( $\mathrm{mm})$, combining data from both sexes and rivers, to translate scale growth into estimates of somatic growth (Fig. S1). We fixed the intercept of this relationship at $40 \mathrm{~mm}$, an estimate of the size at first scale formation (Rich 1920), leading to the following equation:

$$
l_{i}=171.6 \times R_{i}+40
$$

where $l(\mathrm{~mm})$ is the length of fish $i$, and $R(\mathrm{~mm})$ is the total scale radius representing the sum of all annual growth increments. Individual growth increments were then back calculated using

$$
g_{i, a}=171.6 \times r_{i, a}
$$

where $g(\mathrm{~mm})$ is the annual growth increment $a$, and $r(\mathrm{~mm})$ is the scale growth increment width (with the exception of the freshwater growth increment which included the intercept term). While methods that account for individual variation in scale size are generally preferred for back-calculations (Francis 1990), we chose the linear method due to individual variation in the degree of reabsorption of the outer-most margin of the scale during the return migration leading to uncertainty around the original total scale length.

We calculated mean growth of each annual scale increment for every combination of brood year, age at maturity, and sex in both populations (referred to as 'strata' below). To determine if the difference in average growth between male and female fish maturing at the same age was significantly different from 0 , the differences between male and female growth estimates (male - female) for all brood years were compared using 1-sample $t$-tests. We hypothesized that females maturing at the same age as males would demonstrate greater prior growth. For example, males maturing at age 5 represented the central age class of males (i.e. representing the average growing male) whereas females maturing at age 5 were the younger-maturing (i.e. faster-growing) females.

To estimate average cohort growth at a particular age by sex for each river, we weighted the estimates of mean increment growth for each age at maturity by the proportional representation of each age at maturity at the time the growth occurred using

$$
g_{s, b, a}=\sum_{m=\min }^{\max } p_{s, b, m} \times g_{s, b, a, m}
$$

where $g$ is the estimated mean growth for each sex $S$, brood year $b$, and annual growth increment $a$; and $p$ is the estimated proportion, at the time growth occurred, of fish from a given brood year and sex that matured at age $m$ out of all ages at maturity. For example, to estimate average male second-year marine growth $\left(g_{2}\right)$ for each brood year, growth averages were weighted for fish maturing at ages $(m) 4,5$, and 6 . To determine if the difference in average cohort growth of males and females was significantly different from 0 , we again used 1-sample $t$-tests. We also used a similar equation to estimate average growth for the entire cohort including both sexes $\left(g_{b, a}\right)$.

To estimate $p$ in Eq. (3), the distribution of immature fish on different maturation trajectories at distinct time periods was reconstructed from previously completed return estimates from run reconstructions (Siegel 2017) using a constant for marine rearing annual survival $(S)$. Since $S$ is unknown for the study populations, we tested a range of values; $S=1.0,0.7$, and 0.4 . Scenario 1.0 represents no natural mortality (survivors only), 0.7 is typical of values used in other studies (Morita et al. 2005, Pacific Salmon Commission Joint Technical Committee 2015), and 0.4 represents an extreme value. Distributions were reconstructed for all ages between age 7 (the oldest represented age at maturity) and age 4 (the youngest represented age at maturity) using the following:

$$
\mathrm{n}_{y-t}=\frac{n_{y}}{S^{t}}
$$

where $n_{y}$ is the number of fish from a brood year that matured and survived to return to their natal river in year $y, S$ is the annual survival proportion, and $t$ is the number of years of back calculation before maturation (Table S3). This model assumes that all ages at maturity experienced the same constant annual rate of mortality.

Objective 3: quantify and compare PMRNs accounting for growth history in males and females

To determine the relationship between stagespecific growth and age at maturity for each sex, we modeled multidimensional PMRNs for male and female fish separately as binary responses (mature or not mature) using logistic regression. Each 'decision point' during which a fish either matured or did not mature was modeled in each population at the level of individual fish. Since we analyzed 3 age classes for each sex, 2 models were created for each sex in each population, creating a total of 8 models. Males faced 
maturity decisions at ages 4 and 5. Females similarly faced maturity decisions at ages 5 and 6 . To determine if the sexes exhibited distinct maturation reaction norms, we compared the age- 5 models between the sexes.

Scales were sampled from multiple brood years within a single return year, and thus were not proportional to each population's age at maturity composition by brood year. To correct for disproportionate sampling, we considered our dataset to be a stratified random sample according to survey statistics (Lumley 2010). Each age at maturity $(m)$ by brood year $(b)$ combination within each sex $(s)$ was considered a stratum. The assumption in this method is that sampling was representative within each stratum, but not across strata. Strata weights for each mortality scenario (Tables S4-S9) were calculated using the following equation:

$$
w_{m, b, s}=\frac{p_{m, b, s}}{N_{-} s_{m, b, s}}
$$

where $w$ is the stratum weight applied to an individual scale sample, $p$ is the proportion of fish in the stratum out of all fish of a single sex in the brood year estimated using reconstructed distributions (Eq. 4), and $N \_s$ is the number of fish scales measured for the respective strata. Thus, the weight applied to each scale was the proportion of the fish in the modeled maturity decision represented by the measured scale. This weighted each fish within a brood year equally as well as each brood year evenly across the time series. Strata weights were calculated for all survival scenarios ( $S=1.0,0.7$, and 0.4 ), and separate models were run for each scenario (Tables S4-S9). The mean growth value across the time series for that river, age, and sex combination was used to represent strata without scale samples. Strata without samples were rare in the returns (mainly age-7 females, Tables S1 \& S2) and thus had a minimal effect on model fitting.

To make coefficients comparable across models, individual growth increments were standardized by subtracting population-level average growth and dividing by its standard deviation (SD). We used a population-level estimate of mean growth to produce SD anomalies to directly compare PMRNs between males and females. We estimated population-level values for average growth increments by taking the average of growth estimates from all brood years. We estimated average population-level SDs in growth $\left(S D_{a}\right)$ using the following weighting equation:

$$
S D_{a}=\sqrt{\frac{1}{B} \sum_{b=1}^{B} \frac{1}{N_{b}-1} \sum_{h=1}^{k}\left(\sum_{i=1}^{n_{h}}\left(g_{i, h, a}-\bar{g}_{a, b}\right)^{2}\right) \frac{N_{h}}{n_{h}}}
$$

where $N_{b}$ is the population of the entire cohort, $N_{h}$ is the population of stratum $h$ ( 1 through $k$, where $k$ is the number of strata in brood year $b), n_{h}$ is the number of samples from stratum $h\left(1\right.$ to $\left.n_{h}\right), g_{i, h, a}$ is the growth value $(\mathrm{mm})$ of fish $i$ in stratum $h, \bar{g}_{a, b}$ is the estimated cohort mean growth value, and $B$ is the number of brood years in the time series. This equation represents an adaption of the normal SD equation; it adjusts for the stratified nature of sampling by weighting the sum of the squared deviation from the brood year mean growth value in each stratum by the proportion of the cohort represented by the stratum, then weights all brood years evenly by averaging the mean of the estimated squared differences across all brood years. As with the weighting method in the logistic models, the equation assumes that sampling was representative within each stratum, but not across strata.

For each maturity decision model, all standardized growth increments prior to the maturity decision were included as explanatory variables to estimate multidimensional PMRNs accounting for growth history. Brood year was also included (as a fixed categorical variable) to estimate variability in the relationship between growth and maturity among cohorts. Accordingly, the age-4 male maturity decision was modeled as:

$$
\log \left(\frac{P}{1-P}\right)_{i}=\beta_{0}+\beta_{1} g_{f, i}+\beta_{2} g_{1, i}+\beta_{3} g_{2, i}+\beta_{b}+\varepsilon_{i}
$$

where $P$ is the probability of maturing at age 4 for fish $i, g_{f}$ is the standardized freshwater growth increment, $g_{1}$ and $g_{2}$ are the standardized first and second year marine growth increments respectively, and $\beta_{b}$ is a coefficient estimated for each brood year. Full models for age-5 maturity decisions included an additional standardized $g_{3}$ parameter and female age- 6 maturity decision models included additional $g_{3}$ and $g_{4}$ parameters. Model parameters were estimated using maximum likelihood. Additionally, size-at-age models were fit for comparison with growth history models where total length at the time of the maturity decision ( $L$, sum of all growth increments) was used as an explanatory variable in place of individual growth increments. Despite recent research suggesting that adjacent growth increments were correlated in western Alaskan Chinook salmon (Ruggerone et al. 2009), we found minimal correlations between adjacent growth increments in our populations (max $r$ value of 0.16 between $g_{2}$ and $g_{3}$ i see also McPhee et al. 2016). Accordingly, we considered growth increments to be independent in modeling. Models were fit incorporating the above described weights using 
the R package survey (Lumley 2010). All possible variable combinations were compared, and final models were selected using Akaike's information criterion (AIC; Burnham \& Anderson 2004). To isolate the effect of annual growth increments on PMRNs, we used the selected models to project the probability of maturation over a range of standardized growth for the age in question, while setting all other growth values to 0 (mean value) and the brood-year coefficient at its average value.

Objective 4: determine whether the maturation response to growth has changed

Changes over time in the fraction of individuals maturing could be due to plastic responses to changes in growth, or they could be due to changes in the maturation reaction norms. To distinguish between these 2 possibilities, length at age at which a fish has a $50 \%$ probability of becoming mature has commonly been used as a summary statistic to describe changes in PMRNs over time (e.g. Mollet et al. 2007, Kendall et al. 2014). However, in our growth history models, there are numerous combinations of growth that can lead to the same length at age. Accordingly, we used our selected growth history logistic models to predict the probability of maturation at each decision point for a fish with 'average' prior growth. We refer to this metric as the 'probability of maturation with average growth' (PMAG). We defined 'average' growth as the population-level mean growth for each increment over the study period. Since growth was held constant at the mean value, the only thing that varied in the prediction of

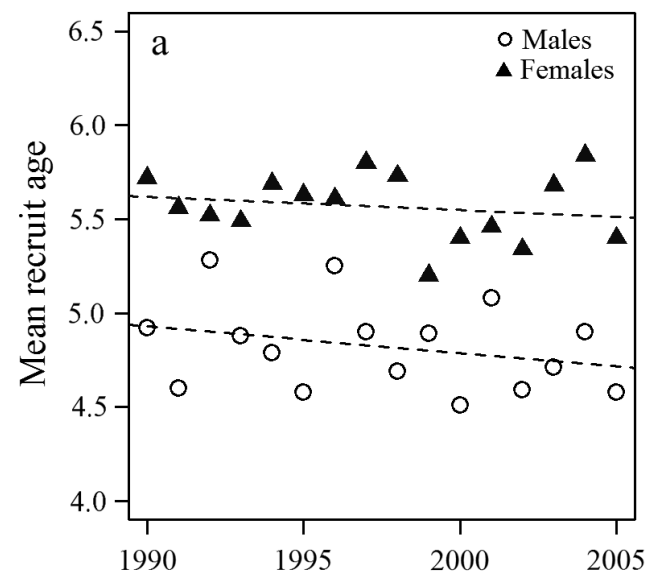

each yearly PMAG was $\beta_{b}$, the coefficient for each brood year from the selected logistic PMRN model. To determine whether PMAG for each maturity decision changed over time, we regressed PMAG on brood year for each mortality scenario.

\section{RESULTS}

Changes in assumed survival rate $(S)$ were found to have a minimal effect on the interpretation of results. While estimates of average growth in higher mortality scenarios were lower due to increased representation of slower growing/later maturing fish, statistical comparisons demonstrated analogous differences between ages at maturity and sexes in all scenarios. Additionally, mortality scenarios had a minimal impact on model selection. Accordingly, we present results for the central $S=0.7$ scenario unless otherwise specified.

\section{Objective 1: characterize temporal trends in age at maturity in males and females}

All regression models estimated trends of decreasing mean age (Fig. 2), although the coefficients were not statistically significant in the Andreafsky River, possibly because of substantial interannual variability and the shorter time series (males; slope =

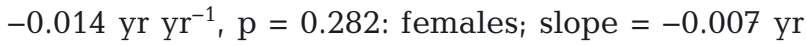
$\left.\mathrm{yr}^{-1}, \mathrm{p}=0.482\right)$. In the Andreafsky River, between brood years 1990 and 2005, the mean age at maturity of male fish was estimated to have declined from 4.9 to $4.7 \mathrm{yr}$, and from 5.6 to $5.5 \mathrm{yr}$ for females. Mean age

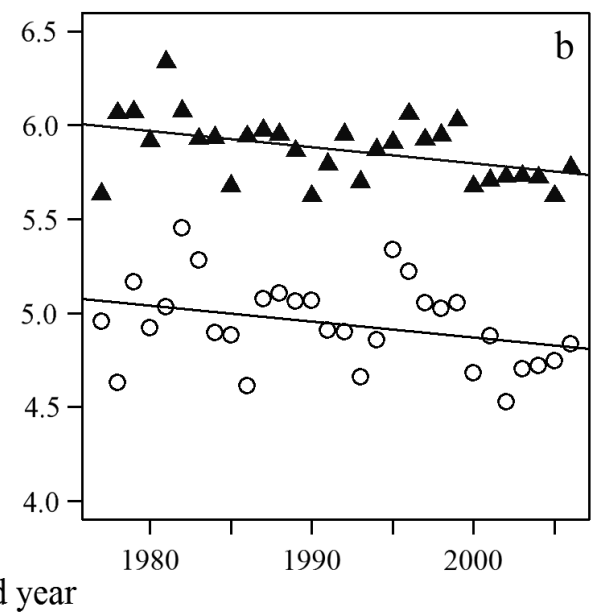

Fig. 2. Estimated average age at maturity by brood year cohort for the Chinook salmon populations of (a) the Andreafsky River and (b) the Kogrukluk River. Estimates are from run reconstructions accounting for harvest in Siegel (2017). Ordinary least squares linear regression fit lines are shown (significant trends $[p<0.10]$ represented with solid lines) 
at maturity declined at a similar rate over the longer time series in the Kogrukluk River (males; slope =

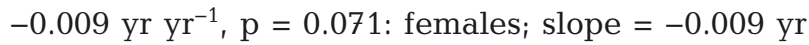
$\left.\mathrm{yr}^{-1}, \mathrm{p}=0.012\right)$. In the Kogrukluk River, between brood years 1977 and 2006, mean age was estimated to have declined from 5.1 to $4.8 \mathrm{yr}$ for males, and from 6.0 to 5.7 yr for females.

\section{Objective 2: estimate and compare average annual growth of males and females}

Estimates of mean growth of males and females for the entire cohort (all ages at maturity combined) were similar between males and females for most increments (Table 1). The most prominent exception was that males grew more than females during $g_{2}$ in both the Andreafsky River (1-sample $t$-test: $\mathrm{p}=0.002$ ) and Kogrukluk River $(\mathrm{p}<0.001)$. Male $g_{2}$ growth averaged $6.1 \%(\sim 11.6 \mathrm{~mm})$ more than female growth in the Andreafsky River and 6.5\% ( 11.7 mm) more than female growth in the Kogrukluk River. Females were estimated to have grown more than males dur- ing $g_{1}$ in the Kogrukluk River ( $\left.\mathrm{p}<0.001\right)$, although the difference was modest $(2.7 \%$ or $\sim 6.3 \mathrm{~mm})$.

As we predicted, average marine growth $\left(g_{1}-g_{4}\right)$ of females was higher than males that matured at the same age (Table 1), leading to larger female size-atage estimates for the same age at maturity (Fig. 3 and see Fig. S2). This relationship held true for all comparisons in both rivers. In the Andreafsky River, 4 out of 7 of the differences were significantly $>0$ while 6 out of 7 of the differences were significantly $>0$ in the Kogrukluk River. Average freshwater growth $\left(g_{f}\right)$ of females was also higher than males that matured at the same age in 3 out of 4 comparisons, although these differences were small and not statistically significant.

\section{Objective 3: quantify and compare PMRNs accounting for growth history in males and females}

Our PRMN models that accounted for growth history out-performed size-at-age models in all cases $(\Delta \mathrm{AIC}>10.0$; Table 2$)$. Selected models demonstra-

Table 1. Mean (SD) back-calculated scale annual growth increment estimates $(g, \mathrm{~mm})$ for each sex and age-at-maturity combination of Chinook salmon from the Andreafsky River (return years 1994-2012) and the Kogrukluk River (return years 1981-2013). Average growth estimates presented from the $S=0.7$ survival scenario. Growth estimates of males and females maturing at the same age, as well as estimated total cohort male and female average estimates (Avg.), were statistically compared within each population. Early-maturing males (age 4) and late-maturing females (age 7), as well as the estimate for the total cohort growth, were not involved in direct statistical comparisons due to having no analogous age class in the opposite sex. Mean differences between males and females that are significantly different from 0 (1-sample $t$-tests) are indicated with asterisks: ${ }^{*} \mathrm{p}<0.05,{ }^{* * *} \mathrm{p}<0.005$

\begin{tabular}{|c|c|c|c|c|c|c|c|}
\hline Age & Sex & $g_{f}$ & $g_{1}$ & $g_{2}$ & $g_{3}$ & $g_{4}$ & $g_{5}$ \\
\hline \multicolumn{8}{|c|}{ Andreafsky } \\
\hline 4 & Male & $101.6(4.7)$ & $248.7(15.5)$ & $215.6(20.1)$ & & & \\
\hline \multirow[t]{2}{*}{5} & Male & $101.1(5.6)$ & $241.4(14.0)^{* * *}$ & $193.0(16.3)$ & $189.4(14.2)$ & & \\
\hline & Female & $101.4(4.5)$ & $249.7(11.6)^{* * *}$ & $200.4(20.5)$ & $192.1(18.0)$ & & \\
\hline \multirow[t]{2}{*}{6} & Male & $99.2(3.6)$ & $232.2(13.6)^{* * *}$ & $171.7(15.3)^{*}$ & $169.0(9.7)^{* * *}$ & $142.1(9.7)$ & \\
\hline & Female & $99.6(3.9)$ & $240.4(12.3)^{* * *}$ & $179.9(12.5)^{*}$ & $177.7(6.9)^{* * *}$ & $143.4(12.2)$ & \\
\hline 7 & Female & $97.1(3.4)$ & $240.1(14.5)$ & $144.3(15.8)$ & $160.3(16.4)$ & $145.7(11.7)$ & $101.2(14.1)$ \\
\hline \multirow[t]{3}{*}{ Avg. } & Male & $101.0(4.2)$ & $242.4(13.6)$ & $194.5(16.3)^{* * *}$ & $183.3(12.6)$ & $142.1(9.7)$ & \\
\hline & Female & $99.8(3.4)$ & $243.0(11.1)$ & $183.0(12.8)^{* * *}$ & $180.7(7.7)$ & $143.5(12.1)$ & $101.2(14.1)$ \\
\hline & Total & $100.5(3.6)$ & $242.5(12.0)$ & $189.3(13.2)$ & $181.7(9.5)$ & $143.4(10.0)$ & \\
\hline \multicolumn{8}{|c|}{ Kogrukluk } \\
\hline 4 & Male & $99.0(4.1)$ & $244.4(14.0)$ & $211.9(20.8)$ & & & \\
\hline \multirow[t]{2}{*}{5} & Male & $97.3(4.9)$ & $232.3(14.2)^{* * *}$ & $188.1(14.9)^{* * *}$ & $184.9(15.7)^{*}$ & & \\
\hline & Female & $97.8(5.0)$ & $248.0(14.0)^{* * *}$ & $206.8(16.8)^{* * *}$ & $193.8(23.8)^{*}$ & & \\
\hline \multirow[t]{2}{*}{6} & Male & $96.9(5.2)$ & $226.6(11.2)^{* * *}$ & $164.5(19.0)^{* * *}$ & $171.4(13.8)^{* * *}$ & $150.6(14.9)$ & \\
\hline & Female & $96.7(5.2)$ & $234.8(11.6)^{* * *}$ & $172.8(15.9)^{* * *}$ & $181.9(11.3)^{* * *}$ & $150.9(16.3)$ & \\
\hline 7 & Female & $95.8(7.9)$ & $240.2(21.3)$ & $136.2(28.2)$ & $158.1(26.5)$ & $152.1(19.3)$ & $109.6(21.3)$ \\
\hline \multirow[t]{3}{*}{ Avg. } & Male & $97.4(3.8)$ & $233.2(11.8)^{* * *}$ & $185.5(16.9)^{* * *}$ & $179.6(13.1)$ & $150.6(14.9)$ & \\
\hline & Female & $96.7(4.7)$ & $239.5(11.6)^{* * *}$ & $173.8(15.8)^{* * *}$ & $181.4(11.9)$ & $151.1(15.6)$ & $109.3(20.1)$ \\
\hline & Total & $97.1(3.7)$ & $235.6(11.1)$ & $180.7(15.9)$ & $180.3(11.4)$ & $150.9(13.0)$ & \\
\hline
\end{tabular}




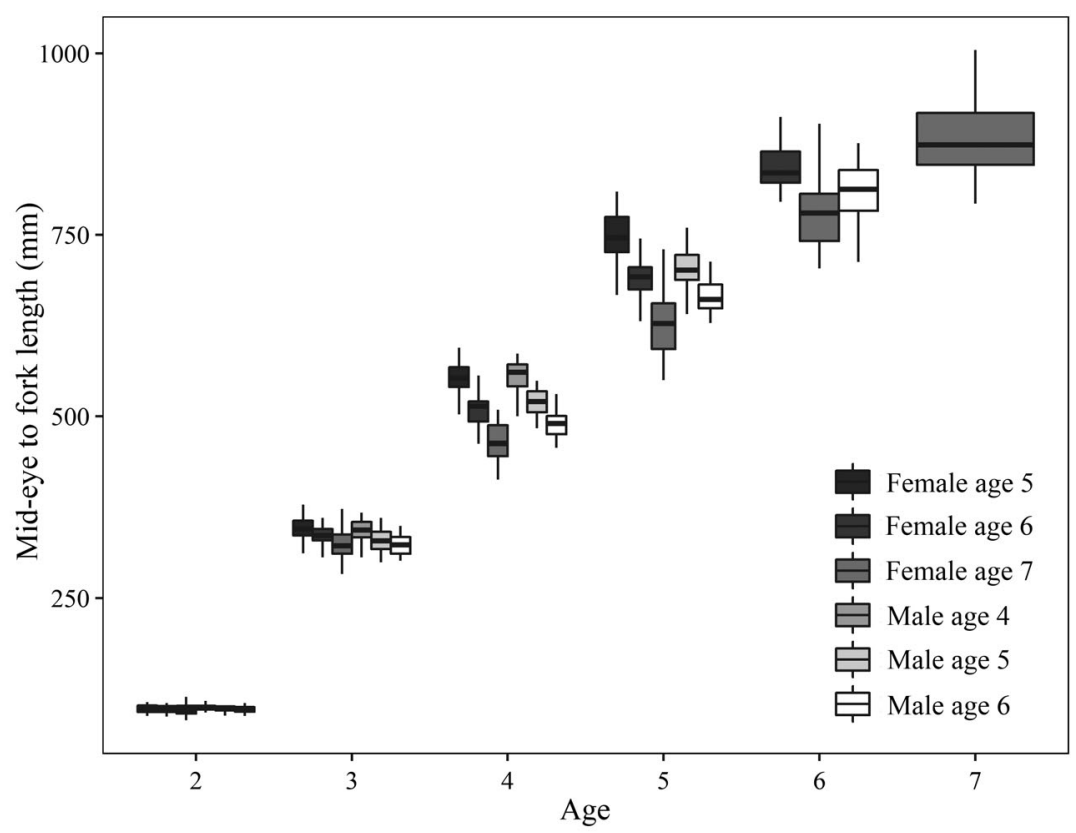

Fig. 3. Average back-calculated size-at-age estimates (mid-eye to fork lengths) of Chinook salmon by sex/age at maturity combinations for all brood years (1977-2006) in the Kogrukluk River. Back-calculations were informed by retrospective scale analysis. Relationship between scale radius and fork length used for back-calculations was estimated using ordinary least squares linear regression with a fixed intercept (mid-eye to fork length $[\mathrm{mm}]=171.6 \times$ radius +40.0$)$. Bar: median (50th percentile); box: interquartile range (25th75th percentile, IQR); whiskers: max./min. within 1.5× IQR above/below IQR

of males and females, the age-5 maturity decision was the only maturity decision common to both sexes. Over all analyzed brood years, a male with the population-level mean growth up until this decision point had a $75 \%$ probability of maturing in the Andreafsky River and a $68 \%$ probability of maturing in the Kogrukluk River, while females accruing the same growth had only $26 \%$ and $11 \%$ probabilities of maturing, respectively.

Although the sexes demonstrated distinct reaction norms for the same age at maturity, the age-5 female and age- 4 male PMRNs were similar (Fig. 4), with $g_{2}$ being the strongest effect for both (Table 3). This suggests that the number of males in a cohort that mature early at age 4 is likely to covary with the number of females that mature early at age 5 the following year due to shared environmental influences. In contrast, PMRNs suggested that females were much less likely to mature late (at age 7 ) in comparison to males matur-

ted disproportionate effects of specific growth increments (Table 3), suggesting that growth history is important in the determination of maturation in the study populations. We found that age at maturity in the study populations was primarily influenced by marine growth in both males and females; freshwater growth was only retained in 1 of the 8 selected models (Table 2). Specifically, the second year in the marine environment appears to be an important period in the determination of age at maturity for western Alaskan Chinook salmon of both sexes; $g_{2}$ had the strongest relationship with age at maturity in each model (Table 3; see also McPhee et al. 2016). All coefficients for growth increments in the selected models were positive, and the selected growthhistory models were generally not well distinguished from full growth-history models by the AIC criterion $(\triangle \mathrm{AIC}<2$, Table 2$)$, suggesting a ubiquitous relationship between faster growth and earlier maturation. The fixed effect for brood year was retained in each model, suggesting among-cohort variability in the probability of maturing with equal growth.

Distinct PMRNs for males and females in both of the study populations were apparent (Fig. 4). Due to the differences in the dominant ages at maturity ing at age 6 , irrespective of growth. Thus, in cohorts experiencing lower than average growth, average age increased to a greater degree in males than in females, although males were still younger on average than females. While the Andreafsky River population demonstrated somewhat higher probabilities of maturing with mean growth compared to the Kogrukluk River population, both populations exhibited similar patterns in multidimensional PMRNs (Fig. 4).

\section{Objective 4: determine whether the maturation response to growth has changed}

The predicted PMAG increased over the period of study for all maturity decisions analyzed in both sexes in the Andreafsky River and Kogrukluk River Chinook salmon populations (Fig. 5). All linear models for each survival scenario demonstrated positive slopes with predicted changes in PMAG ranging from 3.0 to $33.5 \%$ (Table 4 ). These slopes were statistically significant for the Kogrukluk River male age5 , female age-5, and female age- 6 maturity decisions $(\mathrm{p}<0.05)$. 
Table 2. Akaike's information criterion (AIC) selection table for the $S=0.7$ survival scenario modeled Andreafsky River and Kogrukluk River Chinook salmon maturity decisions. While every combination of variables was considered in model selection, only models within 10 AIC points of selected models, size-at-age models, and null models are shown. Individual growth increments are represented by $g_{a}$, with a representing annual growth from freshwater $(f)$ to the fourth year in the ocean (4), while the total length at the age of the maturity decision is represented by $L$ and brood year is represented by $b$

\begin{tabular}{|c|c|c|c|c|c|c|c|}
\hline Decision & Model & $\mathrm{AIC}$ & $\Delta \mathrm{AIC}$ & Decision & Model & AIC & $\Delta \mathrm{AIC}$ \\
\hline Andreafsky & & & & Kogrukluk & & & \\
\hline Male age 4 & $\begin{array}{l}g_{1}+g_{2}+b \\
g_{f}+g_{1}+g_{2}+b \\
L+b \\
\text { Null }\end{array}$ & $\begin{array}{r}874.9 \\
876.9 \\
916.0 \\
1103.9\end{array}$ & \begin{tabular}{r}
\multicolumn{1}{c}{0} \\
2.0 \\
41.2 \\
229.0
\end{tabular} & Male age 4 & $\begin{array}{l}g_{1}+g_{2}+b \\
g_{f}+g_{1}+g_{2}+b \\
L+b \\
\text { Null }\end{array}$ & $\begin{array}{l}1499.7 \\
1501.4 \\
1556.2 \\
1863.1\end{array}$ & \begin{tabular}{r}
\multicolumn{1}{c}{0} \\
1.7 \\
56.5 \\
363.4
\end{tabular} \\
\hline Male age 5 & $\begin{array}{l}g_{1}+g_{2}+g_{3}+b \\
g_{f}+g_{1}+g_{2}+g_{3}+b \\
g_{2}+g_{3}+b \\
g_{f}+g_{2}+g_{3}+b \\
L+b \\
\text { Null }\end{array}$ & $\begin{array}{l}676.2 \\
677.0 \\
685.0 \\
685.0 \\
686.4 \\
813.9\end{array}$ & \begin{tabular}{r}
\multicolumn{1}{c}{0} \\
0.8 \\
8.7 \\
8.8 \\
10.2 \\
137.7
\end{tabular} & Male age 5 & $\begin{array}{l}g_{1}+g_{2}+g_{3}+b \\
g_{2}+g_{3}+b \\
g_{f}+g_{1}+g_{2}+g_{3}+b \\
g_{f}+g_{2}+g_{3}+b \\
L+b \\
\text { Null }\end{array}$ & $\begin{array}{l}1401.7 \\
1401.9 \\
1403.1 \\
1403.2 \\
1455.8 \\
1663.9\end{array}$ & \begin{tabular}{r}
\multicolumn{1}{c}{0} \\
0.3 \\
1.4 \\
1.5 \\
54.1 \\
262.2
\end{tabular} \\
\hline Female age 5 & $\begin{array}{l}g_{1}+g_{2}+g_{3}+b \\
g_{f}+g_{1}+g_{2}+g_{3}+b \\
g_{1}+g_{2}+b \\
g_{2}+g_{3}+b \\
g_{f}+g_{2}+g_{3}+b \\
g_{f}+g_{1}+g_{2}+b \\
L+b \\
\text { Null }\end{array}$ & $\begin{array}{l}733.1 \\
735.2 \\
740.6 \\
740.8 \\
742.3 \\
742.9 \\
751.3 \\
860.2\end{array}$ & \begin{tabular}{r}
\multicolumn{1}{c}{0} \\
2.1 \\
7.5 \\
7.7 \\
9.3 \\
9.8 \\
18.2 \\
127.1
\end{tabular} & Female age 5 & $\begin{array}{l}g_{1}+g_{2}+g_{3}+b \\
g_{f}+g_{1}+g_{2}+g_{3}+b \\
g_{1}+g_{2}+b \\
g_{2}+g_{3}+b \\
g_{f}+g_{2}+g_{3}+b \\
g_{f}+g_{1}+g_{2}+b \\
L+b \\
\text { Null }\end{array}$ & $\begin{array}{r}769.6 \\
770.3 \\
775.4 \\
776.2 \\
777.0 \\
777.2 \\
829.3 \\
1007.7\end{array}$ & \begin{tabular}{r}
\multicolumn{1}{c}{0} \\
0.7 \\
5.8 \\
6.6 \\
7.4 \\
7.6 \\
59.7 \\
238.1
\end{tabular} \\
\hline Female age 6 & $\begin{array}{l}g_{f}+g_{2}+g_{3}+b \\
g_{2}+g_{3}+b \\
g_{1}+g_{2}+g_{3}+b \\
g_{f}+g_{1}+g_{2}+g_{3}+b \\
g_{f}+g_{2}+g_{3}+g_{4}+b \\
g_{2}+g_{3}+g_{4}+b \\
g_{1}+g_{2}+g_{3}+g_{4}+b \\
g_{f}+g_{1}+g_{2}+g_{3}+g_{4}+b \\
g_{f}+g_{2}+b \\
g_{2}+b \\
g_{1}+g_{2}+\mathrm{b} \\
g_{f}+g_{1}+g_{2}+b \\
g_{2}+g_{4}+b \\
g_{f}+g_{2}+g_{4}+b \\
g_{1}+g_{2}+g_{4}+b \\
g_{f}+g_{1}+g_{2}+g_{4}+b \\
L+b \\
\text { Null }\end{array}$ & $\begin{array}{l}156.7 \\
156.9 \\
157.0 \\
157.1 \\
157.7 \\
157.9 \\
158.0 \\
158.2 \\
161.6 \\
161.7 \\
161.9 \\
162.2 \\
162.6 \\
162.6 \\
162.8 \\
163.1 \\
170.7 \\
221.2\end{array}$ & $\begin{array}{r}0 \\
0.3 \\
0.3 \\
0.4 \\
1.1 \\
1.3 \\
1.4 \\
1.6 \\
4.9 \\
5.0 \\
5.2 \\
5.5 \\
5.9 \\
6.0 \\
6.2 \\
6.4 \\
14.1 \\
64.5\end{array}$ & Female age 6 & $\begin{array}{l}g_{1}+g_{2}+g_{3}+b \\
g_{1}+g_{2}+g_{3}+g_{4}+b \\
g_{2}+g_{3}+b \\
g_{2}+g_{3}+g_{4}+b \\
g_{f}+g_{1}+g_{2}+g_{3}+b \\
g_{f}+g_{1}+g_{2}+g_{3}+g_{4}+b \\
g_{f}+g_{2}+g_{3}+b \\
g_{f}+g_{2}+g_{3}+g_{4}+b \\
L+b \\
\text { Null }\end{array}$ & $\begin{array}{l}460.6 \\
460.7 \\
461.5 \\
461.6 \\
462.0 \\
462.1 \\
462.9 \\
463.0 \\
503.6 \\
635.1\end{array}$ & $\begin{array}{r}0 \\
0.1 \\
0.9 \\
1.0 \\
1.4 \\
1.5 \\
2.3 \\
2.4 \\
43.0 \\
174.5\end{array}$ \\
\hline
\end{tabular}

\section{DISCUSSION}

We presented evidence that fish with the same growth have become more likely to mature early in recent years in both the Andreafsky River and Kogrukluk River Chinook salmon populations, across both males and females and over multiple maturity decisions. Similar results between the Kogrukluk River (a Kuskokwim River tributary) and Andreafsky River (a Yukon River tributary) populations suggest that the patterns we describe here may be representative of Chinook salmon in the western Alaskan region. We also found that for these Chinook salmon, traditional PMRN approaches could be improved by incorporating individual growth history (garnered from retrospective analysis of scale archives) and reconstructed age-composition estimates that accounted for harvest.

Our study adds to evidence from past studies (Morita \& Fukuwaka 2006, Kuparinen et al. 2008, McPhee et al. 2016; but see Olsen et al. 2014) suggesting that growth during important life history periods can have a disproportionate influence on age at maturity (e.g. $g_{2}$ in our study populations). Accord- 
Table 3. Logit-scale coefficients for Chinook salmon maturity decision models chosen by Akaike's information criterion selection for the $S=0.7$ survival scenario. Males and females from the Kogrukluk River and Andreafsky River were modeled separately. Standard deviations of calculated brood year coefficients are shown to demonstrate variability in reaction norms across the time series. Variables are defined as in Table 2, and significant values are shown by asterisks: ${ }^{*} \mathrm{p}<0.05,{ }^{* *} \mathrm{p}<0.01,{ }^{* * *} \mathrm{p}<0.005$

\begin{tabular}{|lccccccc|}
\hline Decision model & Intercept & $g_{f}$ & $g_{1}$ & $g_{2}$ & $g_{3}$ & $g_{4}$ & $b$ \\
\hline Andreafsky & & & & & & \\
Male age 4 & $-1.64^{* * *}$ & & $0.35^{* * *}$ & $1.01^{* * *}$ & & \\
Male age 5 & $1.22^{* * *}$ & & $0.37^{* *}$ & $0.75^{* * *}$ & $0.64^{* * *}$ & 0.95 \\
Female age 5 & $-2.20^{* * *}$ & & $0.32^{* *}$ & $0.73^{* * *}$ & $0.29^{* *}$ & 0.83 \\
Female age 6 & $3.97^{* * *}$ & 0.40 & & $1.28^{* * *}$ & $0.69^{* *}$ & 3.79 \\
Kogrukluk & & & & & & \\
Male age 4 & $-2.49^{* * *}$ & & $0.61^{* * *}$ & $0.88^{* * *}$ & & 0.67 \\
Male age 5 & -0.23 & & 0.12 & $0.82^{* * *}$ & $0.36^{* * *}$ & 0.82 \\
Female age 5 & $-3.97^{* * *}$ & & $0.32^{* *}$ & $1.16^{* * *}$ & $0.27^{* *}$ & 1.05 \\
Female age 6 & $2.50^{* * *}$ & & 0.18 & $1.20^{* * *}$ & $0.68^{* * *}$ & 4.70 \\
\hline
\end{tabular}

methods provide a template to achieve this goal in scenarios where only data on survivors to maturation are available, as is generally the case for salmon, which are primarily monitored during their freshwater spawning migrations. Scale samples are commonly collected by salmon management agencies to provide information on age distributions, creating the possibility to widely implement this method to investigate the nature of changing size and age in other salmon populations, and to determine important life history periods influencing age at maturity.

Males and females have distinct drivers of reproductive success, and females in our study populations

ingly, information on growth history should be included in PMRN studies when such data are available in order to better characterize the effects of environmental variation on maturation, and thus more effectively distinguish between genetic and plastic sources of change in age of maturity. Our mature on average nearly a year older than males. Accordingly, we hypothesized that the sexes would exhibit distinct PMRNs and thus modeled them separately. However, while distinct PMRNs between the sexes were clearly demonstrated, our results suggest that age at maturity in both males and females is
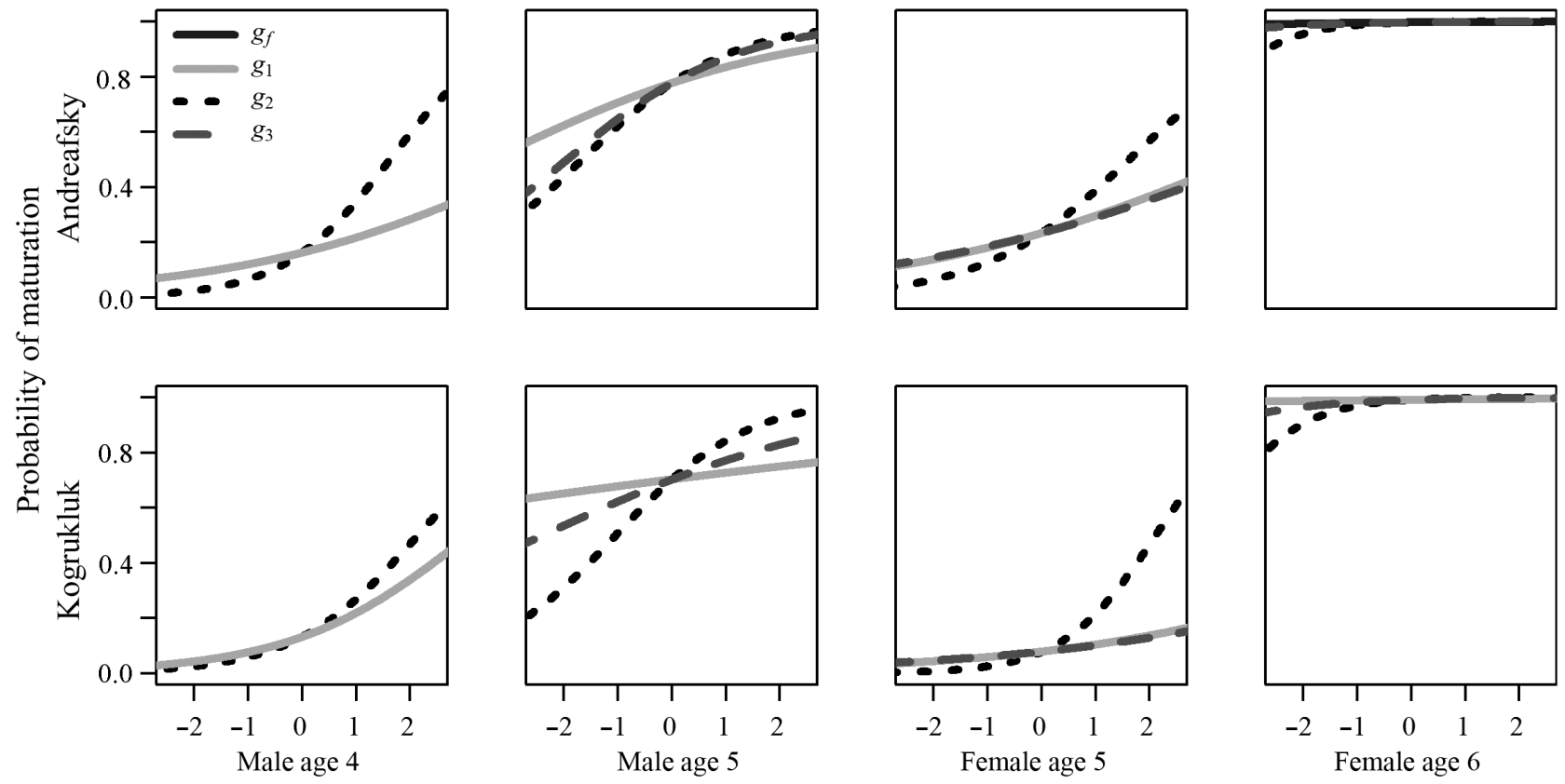

Growth anomalies

Fig. 4. Sex-specific probabilistic maturation reaction norms (PMRNs) isolated for the effects of annual growth increments for the Andreafsky River and Kogrukluk River Chinook salmon populations from the $S=0.7$ survival scenario. Relationships are predicted by Akaike's information criterion (AIC) selected multidimensional PMRN models using retrospective scale analysis to account for growth history. Reaction norms for each annual growth increment are plotted by holding all other stages of growth at the estimated population-level mean value $\left(g_{f}=\right.$ annual freshwater growth increment, $g_{1}=$ first-year marine growth increment, $g_{2}=$ second-year marine growth increment, etc.). Growth anomalies are in units of SD from the mean, calculated by estimating the average SD in population growth estimates within a brood year and mean growth of all brood years 


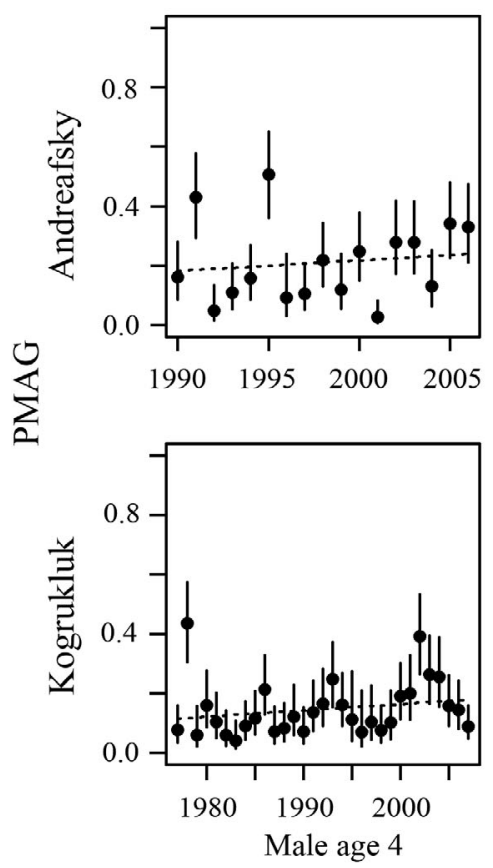

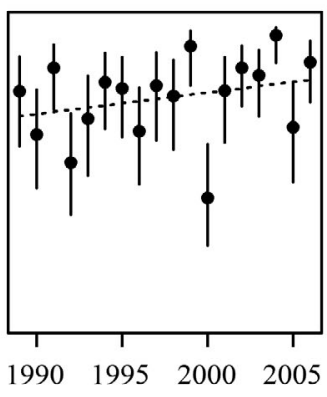

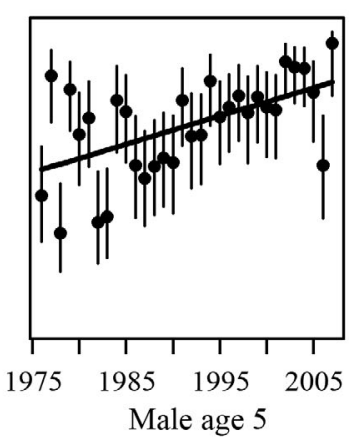

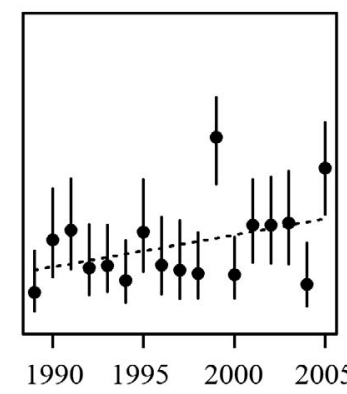
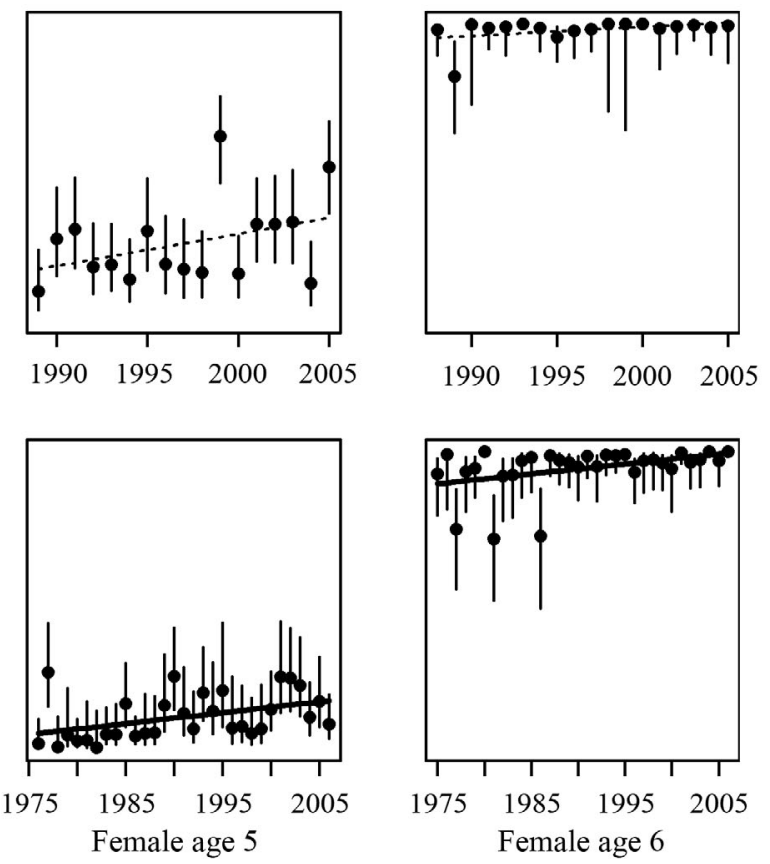

Brood year

Fig. 5. Predicted probabilities of maturation with average growth (PMAG) by brood year for each modeled maturity decision in the Andreafsky River and Kogrukluk River Chinook salmon populations using the central estimate of annual survival ( $S=0.7)$. PMAG was predicted using selected multidimensional probabilistic maturation reaction norm (PMRN) models using retrospective scale analysis to account for growth history. PMAG estimates are shown with regression fit lines and $95 \%$ confidence intervals (solid lines, significant at $\mathrm{p}<0.05$ )

most heavily influenced by the same marine growth period $\left(g_{2}\right)$ in western Alaskan Chinook salmon. This suggests that the plastic effects of environmental experience on age at maturity influence females earlier along the trajectory toward maturation. We also found evidence of sexually dimorphic growth during this important period of age at maturity determination, with lower average growth in females than males. Consistent with this result, past analysis of bycatch samples from the Bering Sea NOAA Fisheries Observer Program found that female Chinook salmon captured following their second year of marine growth were smaller on average than their male counterparts by about $1 \mathrm{~cm}$ (Myers et al. 2010).

Maturation in salmonids has been described as a continuous process, with the potential for completion annually, which is inhibited during critical life history periods if lipid stores are insufficient (Thorpe 1994, Thorpe et al. 1998, Rikardsen et al. 2004). Similar energetic controls on maturation are thought to affect other species such as cyprinids (Uusi-Heikkilä et al. 2011) and percids (Henderson \& Morgan 2002). In a model originally developed for Atlantic salmon, Thorpe et al. (1998) described 2 important periods, one in the fall a year before spawning and one in the spring before spawning, where maturation is either continued or aborted through hormonal control. In alignment with this theory, Morita \& Fukuwaka (2006) found that the last year of growth before the maturity decision had the strongest correlation with age at maturity in chum salmon Oncorhynchus keta in a similar retrospective scale analysis to ours. However, in contrast to Morita \& Fukuwaka's (2006) findings, we identified a more complex and sex-specific relationship in the study populations of Chinook salmon. Only the age-4 male maturity decision was most heavily influenced by growth occurring the year prior to maturation, while all other decisions were better correlated with growth occurring $\geq 2 \mathrm{yr}$ in advance of maturation. Assuming Chinook salmon have similarly timed hormonal maturation switches, as described by Thorpe et al. (1998), our results suggest that the accumulation of energy stores well in advance of these switches has a considerable effect on the ability to surpass energetic thresholds for maturity, particularly for females. The development of eggs and ovaries requires relatively more energy than the development of sperm and testes (Hendry et al. 1999). Accordingly, sexual dimorphic growth during $g_{2}$ may be a consequence of females allocating 
Table 4. Results from linear models for each modeled maturity decision of predicted probabilities of maturing by brood year for a fish with average growth history (PMAG) in the Andreafsky River and the Kogrukluk River Chinook salmon populations. Results for each survival scenario are shown separately $(S=1.0,0.7$, and 0.4$)$. Model slope values are in units of percent change in probability of maturing per year. PMAG start and end represent predicted values at start and end of the respective time series

\begin{tabular}{|c|c|c|c|c|c|c|}
\hline \multirow[t]{2}{*}{ Decision } & \multirow[t]{2}{*}{$S$} & \multirow[t]{2}{*}{ Slope } & \multirow[t]{2}{*}{$\mathrm{R}^{2}$} & \multirow[t]{2}{*}{$\mathrm{p}$} & \multicolumn{2}{|c|}{ PMAG (\%) } \\
\hline & & & & & Start & End \\
\hline \multicolumn{7}{|l|}{ Andreafsky } \\
\hline \multirow[t]{3}{*}{ Male age 4} & 1.0 & 0.450 & 0.02 & 0.605 & 26.5 & 33.7 \\
\hline & 0.7 & 0.355 & 0.02 & 0.613 & 18.2 & 23.9 \\
\hline & 0.4 & 0.191 & 0.02 & 0.638 & 8.9 & 12.0 \\
\hline \multirow[t]{3}{*}{ Male age 5} & 1.0 & 0.532 & 0.07 & 0.304 & 77.3 & 86.4 \\
\hline & 0.7 & 0.720 & 0.08 & 0.264 & 70.0 & 81.2 \\
\hline & 0.4 & 1.000 & 0.10 & 0.210 & 53.2 & 70.3 \\
\hline \multirow[t]{3}{*}{ Female age 5} & 1.0 & 1.165 & 0.14 & 0.135 & 25.4 & 44.1 \\
\hline & 0.7 & 1.074 & 0.15 & 0.126 & 17.5 & 34.7 \\
\hline & 0.4 & 0.821 & 0.15 & 0.121 & 9.0 & 22.2 \\
\hline \multirow[t]{3}{*}{ Female age 6} & 1.0 & 0.200 & 0.15 & 0.111 & 97.0 & 100.0 \\
\hline & 0.7 & 0.299 & 0.15 & 0.107 & 95.4 & 100.0 \\
\hline & 0.4 & 0.445 & 0.15 & 0.118 & 92.2 & 99.7 \\
\hline \multicolumn{7}{|l|}{ Kogrukluk } \\
\hline \multirow[t]{3}{*}{ Male age 4} & 1.0 & 0.276 & 0.04 & 0.272 & 18.3 & 26.6 \\
\hline & 0.7 & 0.213 & 0.04 & 0.264 & 11.5 & 17.9 \\
\hline & 0.4 & 0.139 & 0.07 & 0.166 & 4.6 & 8.8 \\
\hline \multirow[t]{3}{*}{ Male age 5} & 1.0 & 0.811 & 0.29 & 0.002 & 62.7 & 87.9 \\
\hline & 0.7 & 0.949 & 0.30 & 0.001 & 52.9 & 82.3 \\
\hline & 0.4 & 1.079 & 0.31 & 0.001 & 36.4 & 69.9 \\
\hline \multirow[t]{3}{*}{ Female age 5} & 1.0 & 0.533 & 0.19 & 0.014 & 8.0 & 24.1 \\
\hline & 0.7 & 0.366 & 0.18 & 0.016 & 5.2 & 16.2 \\
\hline & 0.4 & 0.192 & 0.19 & 0.015 & 2.4 & 8.2 \\
\hline \multirow[t]{3}{*}{ Female age 6} & 1.0 & 0.226 & 0.16 & 0.023 & 92.9 & 99.9 \\
\hline & 0.7 & 0.332 & 0.16 & 0.021 & 89.1 & 99.4 \\
\hline & 0.4 & 0.570 & 0.19 & 0.014 & 80.5 & 98.2 \\
\hline
\end{tabular}

more energy to storage, in contrast to somatic growth, in advance of maturation in preparation for the higher energetic cost of gonad development. A comparison of energy content between immature males and females sampled at sea, possibly from Bering Sea walleye pollock Gadus chalcogrammus fishery bycatch samples (Stram \& Ianelli 2015), could address this hypothesis.

Past research has demonstrated a strong relationship between smolt size and condition and the age at maturity of Chinook salmon in hatchery (Silverstein et al. 1998, Vøllestad et al. 2004, Larsen et al. 2013, Spangenberg et al. 2014, 2015) and wild populations (Scheuerell 2005, Tattam et al. 2015). These results are similar to our results in that they suggest that age at maturity in Chinook salmon can be influenced by growth conditions well in advance of maturation decisions. However, our results contrast with these past findings in that we found a minimal relationship between freshwater growth and age at maturity, suggesting that western Alaskan Chinook salmon age at maturity is primarily influenced by marine growth conditions. The above cited studies were performed on populations in the contiguous USA, representing the southern portion of the species' range. Southern populations of Chinook salmon tend to have higher freshwater growth rates (Taylor 1990) and mature at an earlier average age in comparison to more northern populations in Canada and Alaska (Myers et al. 1998). Additionally, population-level differences in maturation reaction norms presumably have evolved as a consequence of selection that maximizes the reproductive success of individuals given the local environmental experience (Hutchings 2004). Accordingly, the later influence of growth on maturity timing in western Alaskan Chinook in comparison to other studied populations is likely a consequence of an interaction between genetic differences in maturation reaction norms and environmentally based lower growth rates during early life history, preventing individuals from surpassing thresholds earlier. A common-garden experiment comparing growth and maturation rates between western Alaskan Chinook salmon and southern populations reared under identical conditions (e.g. Spangenberg et al. 2015) would help determine the relative contribution of environmental and genetic sources of variation in age at maturity.

Fisheries-induced evolution has been proposed as a possible driver of declines in the age at maturity of western Alaskan Chinook salmon and potentially could be the source of the described trends in PMAG. There is evidence that the terminal fisheries in the Yukon and Kuskokwim Rivers have been size-selective due to net selectivity (Howard \& Evenson 2010) leading to age-biased harvests. The potential for size-selective fishing to produce declines in average size and age at maturity has been well discussed (Law 2000, Conover et al. 2005, Hard et al. 2008, Uusi-Heikkilä et al. 2015). Theoretical modeling has suggested that selective fisheries could be responsible for declines in average age of western Alaskan Chinook salmon (Bromaghin et al. 2011), and changes in the average age of nearby Bristol Bay sockeye salmon $O$. nerka have been attributed to size-selective fishing (Kendall et al. 2014), though not in Bristol Bay Chinook salmon (Kendall \& Quinn 2011). While not the focus of this investigation, our run reconstructions allowed us to estimate age- 
specific exploitation in the terminal fisheries. We estimated that average exploitation in our study populations was greater on average for older fish in both populations, suggesting a possible source of trends (Siegel 2017). While exploitation was estimated to be higher on average in the Kogrukluk population, size selectivity appeared to be more consistent in the Andreafsky population. The consistency of fisheriesinduced selection pressures in comparison to age declines should be further investigated (e.g. Kendall et al. 2009, 2014, Kendall \& Quinn 2011).

Another possible source of our trends in PMAG could be environmental change altering selective pressures. Primary productivity in the Bering Sea is highly variable, largely driven by the seasonal extent of sea ice determining the timing of the spring phytoplankton bloom with cascading trophic effects on the ecosystem (Coyle et al. 2011, Hunt et al. 2011, Eisner et al. 2014). Climate change is expected to lead to substantial warming and declines in sea-ice extent in the Bering Sea (Wang et al. 2012) and may have already resulted in significant ecosystem-level changes. If the potential for marine growth of older fish diminished, or the probability of mortality for these fish increased, this would have created a selection pressure towards earlier maturation as the reproductive gain of delaying maturation to offset the added mortality risk would have decreased. Additionally, increasing Russian pink salmon O. gorbuscha abundance in the Bering Sea (Ruggerone \& Irvine 2015) has affected growth and maturation of other Pacific salmon species through interspecific competition (Ruggerone et al. 2003, Ruggerone \& Nielsen 2004, Kaga et al. 2013) and may also have had a detrimental effect on Chinook salmon growth and condition as a consequence of substantial diet overlap (Davis et al. 2004).

However, definitively distinguishing between genetic change and plastic responses remains beyond the scope of this study. It should first be noted that because our method was retrospective, we only analyzed information on individuals that survived to maturation. We accounted for a range of annual survival scenarios in our back-calculations $(S=1.0,0.7$, and 0.4 ) and found our results to be robust to differences. However, we had no information on the variability of ocean survival by brood year. Consequently, it is possible that the observed increases in PMAG are a result of an increase in the natural mortality of older maturing fish (ocean 4 and 5), and this remains a limitation of our method. We believe our trends in PMAG are more likely a consequence of declining maturation growth thresholds because this is consis- tent with trends towards smaller size-at-age (Lewis et al. 2015). However, we cannot definitively rule out changes in mortality patterns as a contributing factor to our results.

Additionally, while our methods accounted for growth history, they still cannot be used to conclusively demonstrate genetic change (even assuming unbiased sampling of individuals at the time of the maturation decision) due to an inability to account for all environmental factors that could contribute to a plastic response in age at maturity beyond growth (Kraak 2007, Heino \& Dieckmann 2008). For example, temperature may have an effect independent of its effect on growth on the 'decision' to mature (Kuparinen et al. 2011, Tobin \& Wright 2011, Siegel et al. 2017). Furthermore, as described in the salmonid maturation model presented by Thorpe et al. (1998), higher energetic condition could encourage earlier maturity due to the energetic cost of reproduction (Silverstein et al. 1998, Shearer \& Swanson 2000, Uusi-Heikkilä et al. 2011, Jonsson et al. 2013). Further investigation into the interaction between the Bering Sea ecosystem and growth/condition, and the subsequent effects on maturation is warranted before strong conclusions on the sources of our trends in PMAG can be made. The presented models could easily be extended to include other variables that were found to influence the maturation process (e.g. Tobin \& Wright 2011, Uusi-Heikkilä et al. 2011).

Acknowledgements. Funding for this work was provided by the Alaska Sustainable Salmon Fund (Project no. 44903), the Pollock Cooperative Conservation and Research Center, and the University of Alaska Fairbanks Global Change Student Research Grant award with funds from the Cooperative Institute for Alaska Research. The views expressed in this paper do not necessarily reflect those of the funders. We also thank J. Leon, who measured the female scale samples and performed analyses that laid the foundation for this work. L. Wilson and B. Agler assisted in the acquisition of scales and provided oversight of scale analysis. Z. Liller, L. Dubois, and J. Mears assisted with the acquisition of unpublished data. R. Brown provided insight and helpful comments on earlier versions of the manuscript, and the final version was improved by the constructive comments of 2 anonymous reviewers.

\section{LITERATURE CITED}

Agler BA, Ruggerone GT, Wilson LI, Mueter FJ (2013) Historical growth of Bristol Bay and Yukon River, Alaska chum salmon (Oncorhynchus keta) in relation to climate and inter- and intraspecific competition. Deep Sea Res II 94:165-177

Berejikian BA, Van Doornik DM, Atkins JJ (2011) Alter- 
native male reproductive phenotypes affect offspring growth rates in Chinook salmon. Trans Am Fish Soc 140: 1206-1212

* Bigler BS, Welch DW, Helle JH (1996) A review of size trends among North Pacific salmon (Oncorhynchus spp.). Can J Fish Aquat Sci 53:455-465

Borgerson L, Clemens B, Bowden K, Gunckel S (2014) Fish life history analysis project: methods for scale analysis. Inform Rep 2014-10. Oregon Department of Fish and Wildlife, Corvallis, OR

Bromaghin JF, Nielson RM, Hard JJ (2011) A model of Chinook salmon population dynamics incorporating sizeselective exploitation and inheritance of polygenic correlated traits. Nat Resour Model 24:1-47

Burnham KP, Anderson DR (2004) Multimodal inference: understanding AIC and BIC in model selection. Sociol Methods Res 33:261-304

Carlson SM, Seamons TR (2008) A review of quantitative genetic components of fitness in salmonids: implications for adaptation to future change. Evol Appl 1:222-238

Conover DO, Arnott SA, Walsh MR, Munch SB (2005) Darwinian fishery science: lessons from the Atlantic silverside (Menidia menidia). Can J Fish Aquat Sci 62:730-737

Coyle KO, Eisner LB, Mueter FJ, Pinchuk AI and others (2011) Climate change in the southeastern Bering Sea: impacts on pollock stocks and implications for the oscillating control hypothesis. Fish Oceanogr 20:139-156

Davis ND, Fukuwaka M, Armstrong JL, Myers KW (2004) Salmon food habits studies in the Bering Sea, 1960 to present. North Pac Anadromous Fish Comm Tech Rep 6: 24-28

Dubois L (2013) Origins of Chinook salmon in the Yukon River fisheries, 2010. Alaska Dep Fish Game Fish Data Ser 13-53. Alaska Department of Fish and Game, Division of Sport Fish and Commercial Fisheries, Anchorage, AK

Eisner LB, Napp JM, Mier KL, Pinchuk AI, Andrews AG (2014) Climate-mediated changes in zooplankton community structure for the eastern Bering Sea. Deep Sea Res II 109:157-171

Fobes N (1995) Reaching home: Pacific salmon, Pacific people. Alaska Northwest Books, Seattle, WA

Francis RICC (1990) Back calculation of fish length: a critical review. J Fish Biol 36:883-902

Fukuwaka M, Kaeriyama M (1997) Scale analyses to estimate somatic growth in sockeye salmon, Oncorhynchus nerka. Can J Fish Aquat Sci 54:631-636

Grift RE, Heino M, Rijnsdorp AD, Kraak SBM, Dieckmann U (2007) Three-dimensional maturation reaction norms for North Sea plaice. Mar Ecol Prog Ser 334:213-224

Hagen PT, Oxman DS, Agler BA (2001) Developing and deploying a high resolution imaging approach for scale analysis. NPAFC Doc 567. Mark, Tag, and Age Lab, Alaska Department of Fish and Game, Juneau, AK

Hankin DG, Nicholas JW, Downey TW (1993) Evidence for inheritance of age of maturity in Chinook salmon (Oncorhynchus tshawytscha). Can J Fish Aquat Sci 50:347-358

Hard JJ, Gross MR, Heino M, Hilborn R, Kope RG, Law R, Reynolds JD (2008) Evolutionary consequences of fishing and their implications for salmon. Evol Appl 1:388-408

Heino M, Dieckmann U (2008) Detecting fisheries-induced life-history evolution: an overview of the reaction-norm approach. Bull Mar Sci 83:69-93

Heino M, Dieckmann U, Godø OR (2002) Measuring probabilistic reaction norms for age and size at maturation. Evolution 56:669-678
Heino M, Díaz Pauli B, Dieckmann U (2015) Fisheriesinduced evolution. Annu Rev Ecol Evol Syst 46:461-480

* Henderson BA, Morgan GE (2002) Maturation of walleye by age, size and surplus energy. J Fish Biol 61:999-1011

* Hendry AP, Berg OK, Quinn TP (1999) Condition dependence and adaptation-by-time: breeding date, life history, and energy allocation within a population of salmon. Oikos 85:499-514

Howard KG, Evenson DF (2010) Yukon River Chinook salmon comparative mesh size study. Alaska Dep Fish Game Fish Data Ser 10-92. Alaska Department of Fish and Game, Division of Sport Fish, Research and Technical Services, Anchorage, AK

*Hunt GL Jr, Coyle KO, Eisner LB, Farley EV and others (2011) Climate impacts on eastern Bering Sea foodwebs: a synthesis of new data and an assessment of the Oscillating Control Hypothesis. ICES J Mar Sci 68:1230-1243

Hutchings JA (2004) Norms of reaction and phenotypic plasticity in salmonid life histories. In: Hendry AP, Stearns SC (eds) Evolution illuminated: salmon and their relatives. Oxford University Press, New York, NY, p 154-174

* Jeffrey KM, Côté IM, Irvine JR, Reynolds JD (2017) Changes in body size of Canadian Pacific salmon over six decades. Can J Fish Aquat Sci 74:191-201

* Jonsson B, Jonsson N, Finstad AG (2013) Effects of temperature and food quality on age and size at maturity in ectotherms: an experimental test with Atlantic salmon. J Anim Ecol 82:201-210

Kaga T, Sato S, Azumaya T, Davis ND, Fukuwaka M (2013) Lipid content of chum salmon Oncorhynchus keta affected by pink salmon $O$. gorbuscha abundance in the central Bering Sea. Mar Ecol Prog Ser 478:211-221

Kendall NW, Quinn TP (2011) Length and age trends of Chinook salmon in the Nushagak River, Alaska, related to commercial and recreational fishery selection and exploitation. Trans Am Fish Soc 140:611-622

Kendall NW, Hard JJ, Quinn TP (2009) Quantifying six decades of fishery selection for size and age at maturity in sockeye salmon. Evol Appl 2:523-536

K Kendall NW, Dieckmann U, Heino M, Punt AE, Quinn TP (2014) Evolution of age and length at maturation of Alaskan salmon under size-selective harvest. Evol Appl $7: 313-322$

Kraak SBM (2007) Does the probabilistic maturation reaction norm approach disentangle phenotypic plasticity from genetic change? Mar Ecol Prog Ser 335:295-300

Kuparinen A, Merilä J (2007) Detecting and managing fisheries-induced evolution. Trends Ecol Evol 22:652-659

K Kuparinen A, O'Hara RB, Merilä J (2008) The role of growth history in determining age and size at maturation in exploited fish populations. Fish Fish 9:201-207

Kuparinen A, Cano JM, Loehr J, Herczeg G, Gonda A, Merilä J (2011) Fish age at maturation is influenced by temperature independently of growth. Oecologia 167: 435-443

K Larsen DA, Harstad DL, Strom CR, Johnston MV and others (2013) Early life history variation in hatchery-origin and natural-origin spring Chinook salmon in the Yakima River, Washington. Trans Am Fish Soc 142:540-555

KLaw R (2000) Fishing, selection, and phenotypic evolution. ICES J Mar Sci 57:659-668

Law R (2007) Fisheries-induced evolution: present status and future directions. Mar Ecol Prog Ser 335:271-277

KLewis B, Grant WS, Brenner RE, Hamazaki T (2015) Changes in size and age of Chinook salmon Oncorhyn- 
chus tshawytscha returning to Alaska. PLOS ONE 10: e0130184

Liller ZW, Brodersen AR, Truesdale CL (2015) Salmon age, sex, and length catalog for the Kuskokwim area, 2013. Reg Inf Rep 3A15-07. Final Report for Project 10-303. USFWS, Office of Subsistence Management Fisheries Resource Monitoring Program. Alaska Department of Fish and Game, Division of Commercial Fisheries, Anchorage, AK

Lord N (2016) Made of salmon: Alaska stories from the salmon project. University of Alaska Press, Fairbanks, AK

Lumley T (2010) Complex surveys: a guide to analysis using R. Wiley, Hoboken, NJ

McPhee MV, Leon JM, Wilson LI, Siegel JE, Agler BA (2016) Changing growth and maturity in western Alaskan Chinook salmon Oncorhynchus tshawytscha, brood years 1975-2005. North Pac Anadromous Fish Comm Bull 6: 307-327

Mears JD (2013) Abundance and run timing of adult Pacific salmon in the East Fork Andreafsky River, Yukon Delta National Wildlife Refuge, Alaska, 2012. US Fish Wildl Alaska Fish Data Ser 2013-9. Fairbanks Fish and Wildlife Field Office, Fairbanks, AK

Mollet FM, Kraak SBM, Rijnsdorp AD (2007) Fisheriesinduced evolutionary changes in maturation reaction norms in North Sea sole Solea solea. Mar Ecol Prog Ser 351:189-199

Morita K, Fukuwaka MA (2006) Does size matter most? The effect of growth history on probabilistic reaction norm for salmon maturation. Evolution 60:1516-1521

Morita K, Morita SH, Fukuwaka M, Matsuda H (2005) Rule of age and size at maturity of chum salmon (Oncorhynchus keta): implications of recent trends among Oncorhynchus spp. Can J Fish Aquat Sci 62:2752-2759

Myers JM, Kope GH, Bryant GJ, Teel D and others (1998) Status review of Chinook salmon from Washington, Idaho, Oregon and California. Tech Memo NMFS-NWFSC-35. US Department of Commerce, NOAA, Seattle, WA

Myers KW, Walker RV, Davis ND, Armstrong JL, Fournier WJ, Mantua NJ, Raymond-Yakoubian J (2010) Climateocean effects on AYK Chinook salmon. 2010 Arctic Yukon Kuskokwim Sustainable Salmon Initiative Project Final Product. SAFS-UW-1003. School of Aquatic and Fishery Sciences, University of Washington, Seattle, WA

Olsen EM, Serbezov D, Vøllestad LA (2014) Probabilistic maturation reaction norms assessed from mark-recaptures of wild fish in their natural habitat. Ecol Evol 4: $1601-1610$

Otero J, Jensen AJ, L'Abée-Lund JH, Stenseth NC, Storvik GO, Vøllestad LA (2012) Contemporary ocean warming and freshwater conditions are related to later sea age at maturity in Atlantic salmon spawning in Norwegian rivers. Ecol Evol 2:2192-2203

Pacific Salmon Commission Chinook Committee (2015) 2014 exploitation rate analysis and model calibration, Vol 1. Pacific Salmon Comm TCCHINOOK(15)-1 V. 1. www. psc.org/download/35/chinook-technical-committee/2132/ tcchinook15-1_v1.pdf

Quinn TP (2005) The behavior and ecology of Pacific salmon and trout. University of Washington Press, Seattle, WA

R Core Team (2014) R: a language for environmental and statistical computing. R Foundation for Statistical Computing, Vienna

Rich WH (1920) Early history and seaward migration of Chinook salmon in the Columbia and Sacramento rivers.
Bull US Bur Fish 37:1-73

Ricker WE (1981) Changes in the average size and average age of Pacific salmon. Can J Fish Aquat Sci 38:1636-1656

* Rikardsen AH, Thorpe JE, Dempson JP (2004) Modeling the life history variation of Arctic charr. Ecol Freshw Fish 13: 305-311

Ruggerone GT, Irvine JR (2015) Provisional abundance estimates of adult hatchery and wild pink, chum, and sockeye salmon by region of the North Pacific, 1952-2010. North Pacific Anadromous Fish Com Doc 1594. NPAFC, Vancouver

* Ruggerone GT, Nielsen JL (2004) Evidence for competitive dominance of pink salmon (Oncorhynchus gorbuscha) over other salmonids in the North Pacific Ocean. Rev Fish Biol Fish 14:371-390

* Ruggerone GT, Zimmermann M, Myers KW, Nielsen JL, Rogers DE (2003) Competition between Asian pink salmon (Oncorhynchus gorbuscha) and Alaskan sockeye salmon (O. nerka) in the North Pacific Ocean. Fish Oceanogr 12:209-219

* Ruggerone GT, Nielsen JL, Bumgarner J (2007) Linkages between Alaskan sockeye salmon abundance, growth at sea, and climate, 1955-2002. Deep Sea Res II 54: 2776-2793

Ruggerone GT, Nielsen JL, Agler BA (2009) Linking marine and freshwater growth in western Alaska Chinook salmon Oncorhynchus tshawytscha. J Fish Biol 75: 1287-1301

Scheuerell MD (2005) Influence of juvenile size on the age at maturity of individually marked wild Chinook salmon. Trans Am Fish Soc 134:999-1004

* Sharpe DMT, Hendry AP (2009) Life history change in commercially exploited fish stocks: an analysis of trends across studies. Evol Appl 2:260-275

Shearer KD, Swanson P (2000) The effect of whole body lipid on early sexual maturation of $1+$ age male Chinook salmon (Oncorhynchus tshawytscha). Aquaculture 190: 343-367

Shearer K, Parkins P, Gadberry B, Beckman B, Swanson P (2006) Effects of growth rate/body size and a low lipid diet on the incidence of early sexual maturation in juvenile male spring Chinook salmon (Oncorhynchus tshawytscha). Aquaculture 252:545-556

Siegel JE (2017) Determinants of life history variability in the Chinook salmon (Oncorhynchus tshawytscha) of western Alaska. MSc thesis, University of Alaska Fairbanks

Siegel JE, McPhee MV, Adkison MD (2017) Evidence that marine temperatures influence growth and maturation of western Alaskan Chinook salmon Oncorhynchus tshawytscha. Mar Coast Fish 9:441-456

Silverstein JT, Shearer KD, Dickhoff WW, Plisetskaya EM (1998) Effects of growth and fatness on sexual development of Chinook salmon (Oncorhynchus tshawytscha) parr. Can J Fish Aquat Sci 55:2376-2382

Spangenberg D, Larsen DA, Gerstenberger R, Brun C, Beckman BR (2014) The effects of variation in rearing conditions on growth, smolt development, and minijack rate in yearling Chinook salmon: a hatchery scale experiment. Trans Am Fish Soc 143:1220-1230

Spangenberg DK, Larsen DA, Gerstenberger R, Brun C and others (2015) Stock differences in growth, smolting, and early male maturation in hatchery spring Chinook salmon: a common-garden experiment. N Am J Fish Manag $35: 1090-1100$ 
Stearns SC (1992) The evolution of life histories. Oxford University Press, Oxford

Stram DL, Ianelli JN (2015) Evaluating the efficacy of salmon bycatch measures using fishery-dependent data. ICES J Mar Sci 72:1173-1180

Tattam IA, Ruzycki JR, McCormick JL, Carmichael RW (2015) Length and condition of wild Chinook salmon smolts influence age at maturity. Trans Am Fish Soc 144: $1237-1248$

Taylor EB (1990) Environmental correlates of life-history variation in juvenile Chinook salmon, Oncorhynchus tshawytscha (Walbaum). J Fish Biol 37:1-17

Thorpe JE (1994) Reproductive strategies in Atlantic salmon, Salmo salar L. Aquacult Fish Manag 25:77-87

Thorpe JE, Mangel M, Metcalfe NB, Huntingford FA (1998) Modelling the proximate basis of salmonid life-history variation, with application to Atlantic salmon, Salmo salar L. Evol Ecol 12:581-599

Tobin D, Wright PJ (2011) Temperature effects on female maturation in a temperate marine fish. J Exp Mar Biol Ecol 403:9-13

* Uusi-Heikkilä S, Kuparinen A, Wolter C, Meinelt T, O'Toole AC, Arlinghaus R (2011) Experimental assessment of the probabilistic maturation reaction norm: condition matters. Proc R Soc B 278:709-717

Uusi-Heikkilä S, Whiteley AR, Kuparinen A, Matsumura S

Editorial responsibility: Stylianos Somarakis, Heraklion, Greece and others (2015) The evolutionary legacy of size-selective harvesting extends from genes to populations. Evol Appl 8:597-620

V Vainikka A, Gårdmark A, Bland B, Hjelm J (2009) Two- and three-dimensional maturation reaction norms for the eastern Baltic cod, Gadus morhua. ICES J Mar Sci 66: 248-257

* Vøllestad LA, Peterson J, Quinn TP (2004) Effects of freshwater and marine growth rates on early maturity in male coho and Chinook salmon. Trans Am Fish Soc 133: 495-503

* Walker BM, Sutton TM (2016) Growth-increment formation using otoliths and scales for age-0 Chinook salmon. N Am J Fish Manag 36:995-999

*Wang M, Overland JE, Stabeno P (2012) Future climate of the Bering and Chukchi Seas projected by global climate models. Deep Sea Res II 65-70:46-57

Wells BK, Grimes CB, Sneva JG, McPherson S, Waldvogel JB (2008) Relationships between oceanic conditions and growth of Chinook salmon (Oncorhynchus tshawytscha) from California, Washington, and Alaska, USA. Fish Oceanogr 17:101-125

Williams DL, Shelden CA (2011) Kogrukluk River salmon studies, 2010. Alaska Dep Fish Game Fish Data Ser 10-49. Alaska Department of Fish and Game, Division of Commercial Fisheries, Anchorage, AK

Submitted: July 21, 2017; Accepted: March 12, 2018

Proofs received from author(s): April 24, 2018 